\title{
The Latest Modeling and Implementation Techniques for an Extended Production Management System
}

\author{
V. Stich, A. Kees. \\ Forschungsinstitut für Rationalisierung e.V. (FIR), \\ Pontdriesch 14/16, D-52062 Aachen, Germany, \\ Tel.: ++49-241-47705-22,Fax: ++49-241-402401, \\ st@fir.rwth-aachen.de,ke@fir.rwth-aachen.de
}

\begin{abstract}
In the course of the project METHPRO, a reference process model was developed to integrate planning and control of production, maintenance and quality management. These reference processes were used to design a software system. The data and the functions that are to be managed by the software were derived from the process model. Based upon these classical models, an extended objectoriented PPC-system-prototype was developed. To ensure that the prototype complies with the reference process model, a method was conceived which provides a systematic procedure to derive an object-oriented model out of classical models.
\end{abstract}

Keywords

Production Management, Maintenance, Quality Management, Process Modeling, Object-Oriented Modeling 


\section{INTRODUCTION}

Existing software systems for the production planning and control (PPC-systems) suffer from an insufficient support for maintenance and quality assurance features. This leads to deficits in processing production, maintenance and quality assurance orders (Figure 1). Identical or similar tasks are supported by non-harmonized processes or even different software systems (e. g. order capturing). This leads to conflicts in ressource planning (e. g. when staff is qualified for both production and quality management) and deficits in supporting dependent processes (e. g. release of test order when a completion note has been captured). Apart from that, information on identical business objects are not being shared accordingly (e. g. supplier evaluation in maintenance and production systems).

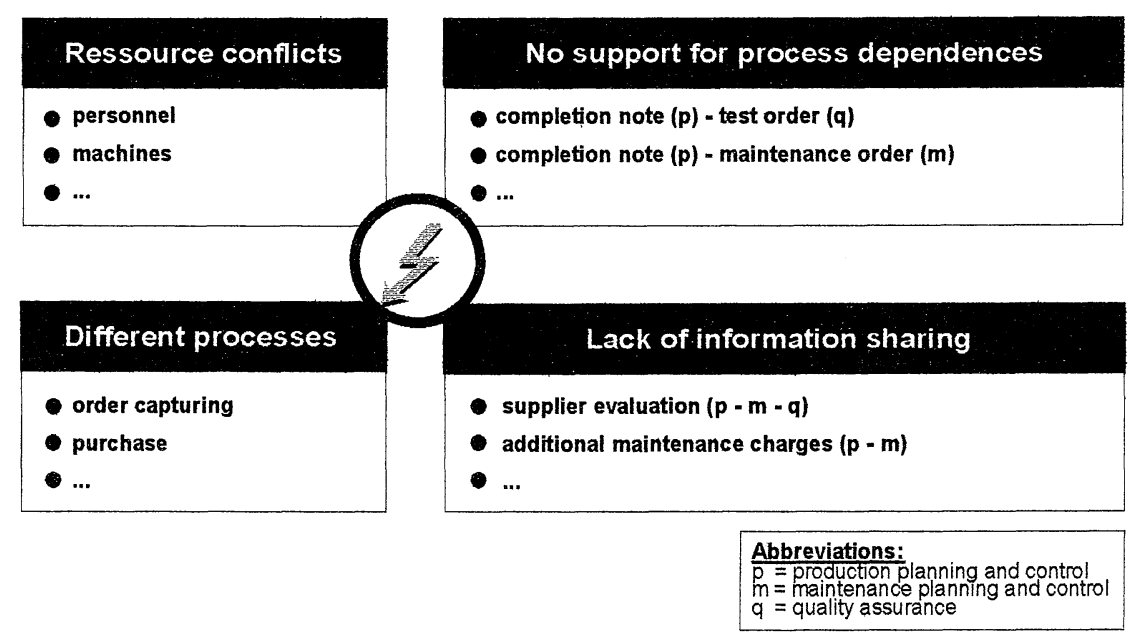

Figure 1 Deficits.

As a consequence, the respective processes can not be synchronized and synergisms can not be utilized fully. Therefore, the BMBF (Bundesministerium für Bildung und Forschung) started the project METHPRO to integrate production planning and control, maintenance planning and control and quality assurance (Kees 1996).

\section{INTEGRATION OF PRODUCTION, MAINTENANCE AND QUALITY ASSURANCE}

To proceed production, maintenance and quality assurance orders efficiently, a reference process model was developed which integrates and synchronizes the technical order processing in these three domains to a maximum degree. 
Furthermore, an integrated order processing makes a vast exhaustion of emerging synergisms possible (Figure 2).

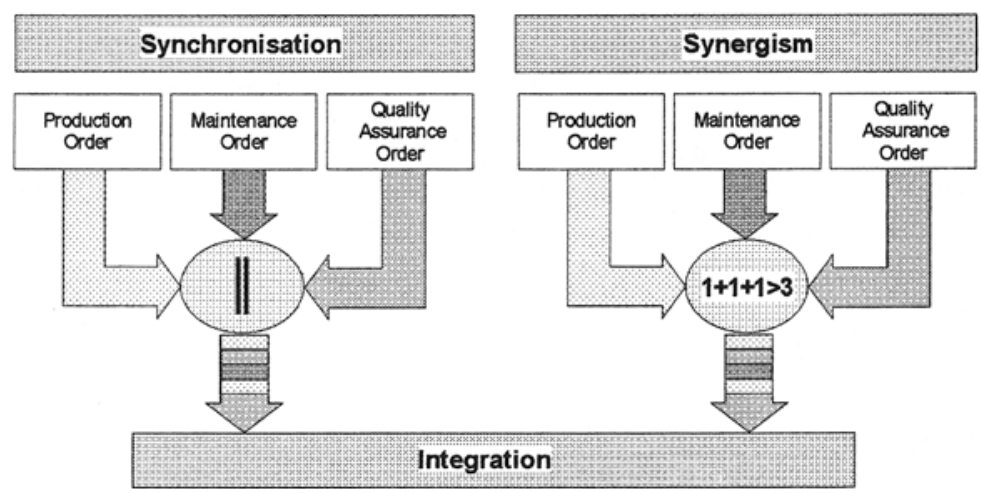

Figure 2 Synchronisation and synergy.

Referring to the technical order processing, the terms synchronisation, synergy and integration were defined as followed (Kees 1998a):

- A process synchronisation describes the harmonization of processes which originally comprised different process elements or the same process elements in a different sequence. After a successful synchronisation the respective processes consist of analogous or identical process elements.

- A process synergism refers to the concurrence of process elements which enhance the flow of information within the superordinate process. The advantages which occur due to the improvement of the flow of information are called process synergies.

- Process integration combines appropriate processes and reduces the number of process elements.

Examples for process integrations are listed in Table 1.

The processes are generated and documented with the process modeling tool AENEIS (Ipro 1997). To provide software support for the reference processes, the data and the functions that need to be available were derived from the elements of the process model (Figure 3).

The overall structure of the processes, data and functions is documented in the task model (Figure 4).

The architecture of the METHPRO-model complies with the Aachener PPCmodel (Luczak et al. 1998). 
Table 1 Integrated order processing for production, maintenance and quality assurance

\begin{tabular}{lll}
\hline $\begin{array}{l}\text { Production - Quality Assurance } \\
\text { Purchase }\end{array}$ & $\begin{array}{l}\text { CAQ-data based selection of suppliers } \\
\text { PPC- and CAQ-data based calculation of quality } \\
\text { costs }\end{array}$ \\
Order coordination & $\begin{array}{l}\text { Coordination of threshold values for } \\
\text { construction, project engineering, quality } \\
\text { planning etc. }\end{array}$ \\
\hline $\begin{array}{l}\text { Production - Maintenance } \\
\text { Ressource Planning }\end{array}$ & - Integrated planning and booking of capacities \\
Maintenance Planning & - $\begin{array}{l}\text { Machine idleness: quick identification of } \\
\text { overdue maintenance activites }\end{array}$ \\
- Return data capturing: generation of \\
maintenance orders depending on the number of \\
items produced \\
Tool Production Planning & $\begin{array}{l}\text { Master-Production-Schedule-controlled } \\
\text { processing of tool production orders }\end{array}$ \\
\hline
\end{tabular}

Quality Assurance - Maintenance

- Planning of the due dates of maintenance orders

- Planning of maintenance intervals

- Planning of reliability-features

Maintenance - Quality Assurance

- Planning of the due dates of quality assurance orders

- Planning of inspection features

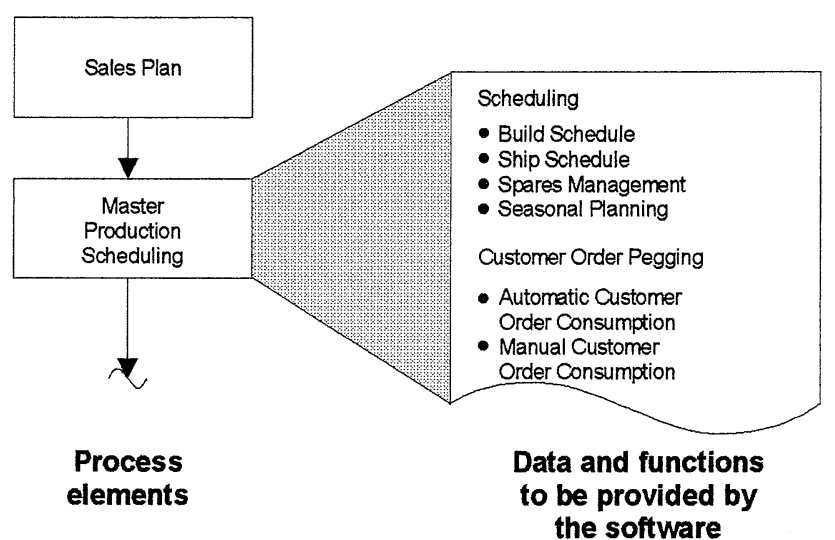

Figure 3 Derivation of the data model and the function model from the processes. 


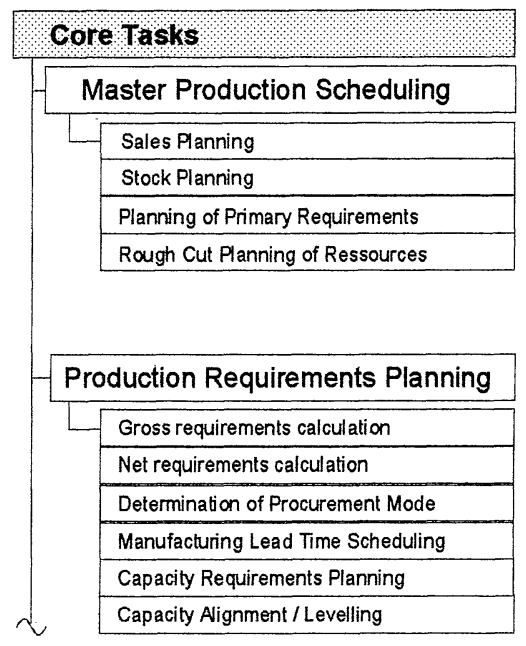

\begin{tabular}{|l|}
\hline Overall Tasks $\mathbf{}, \mathbf{}$ \\
\hline Coordination of Orders \\
\hline \\
\hline Quotation Processing \\
\hline Order Specification \\
\hline Rough-Cut Planning of Orders \\
\hline Rough-Cut Planning of Ressources (to orders) \\
\hline Order Control \\
\hline Inventory Management \\
\hline Contol of Inventory Movements \\
\hline Inventory Control \\
\hline Management of Stores and Storage Bins \\
\hline Lot Control \\
\hline Monitoring \\
\hline Stocktaking \\
\hline
\end{tabular}

Figure 4 Task model.

\section{OBJECT-ORIENTED MODELING}

Based upon theses three models, an object-oriented software system was developed to support an integrated planning and control of production, maintenance and quality management (extended PPC-system). The development process for objectoriented software systems consists of

- object-oriented analysis,

- object-oriented design,

- object-oriented realisation (Booch 1994, Jacobson et al. 1994, Rumbaugh et al. 1991, Wirfs-Brock et al. 1993).

Since the class diagram of the object-oriented analysis model determines the static structure of the developed software system, the analysis class diagram is of fundamental importance for the whole software development process. To ensure that the class diagram of the object-oriented model and the underlying models classical models (data / function / process model) are consistent, a method was developed to derive the analysis class diagram from these modells. This method is based upon identifying communicative units in process models. Each communicative unit can be encapsulated and can thus serve as a basis for the class definition in the object-oriented analysis model. Furthermore, this so-called communication-oriented method provides rules to complete the object-oriented analysis model step by step, e. g. as to attributes, operations and relations between 
classes (Kees 1998b). Figure 5 gives an overview of the communication-oriented method.

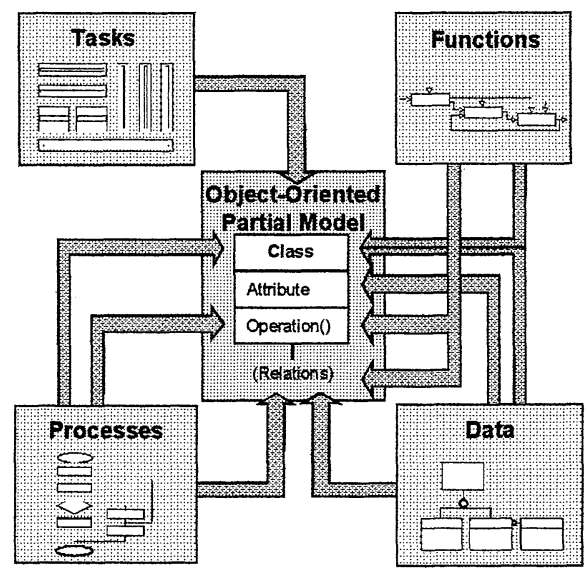

Figure 5 Overview of the communication-oriented derivation of the objectoriented model.

The object-oriented model which results from this derivation can be characterized as an initial object-oriented analysis model. It was extended to a full object-oriented design model by the means of classical object-oriented modeling techniques.

\section{SYSTEM ARCHITECTURE AND REALISATION OF THE PROTOTYPE}

As to the architecture of the software prototype, the following requirements were defined (Kees et al. 1997):

- inter- and intranet-facilities are to be provided;

- support of standard-protocols;

- platform-independency;

- scalability;

- modularity.

The growing importance of the programming language Java in the intra- and internet domain as well as the platform-independency of Java-applications lead to the decision to prefer Java to $\mathrm{C}++$ for the realisation of the prototype. To ensure that the developed software supports standard-protocols it was decided to comply with the OMG-standard CORBA (Redlich 1996). In the course of the project, the CORBA-implementation OrbixWeb was used. The development process itself was performed with the object-oriented CASE-tool StP (Aonix 1997). Since StP showed certain deficits in developing Java-applications (e. g. incremental software generation), the tool had to be modified accordingly. Furthermore, the following tools were used to support the realization of the prototype: GUI-builder for the clients (Jfactory, Borland 1996), server desktop (Symantec Café, Jardin et al. 
1997) and configuration management (Source Integrity, MKS 1997). A highlight of the prototype is the use of the object-oriented database Poet (Poet 1997).

The software architecture consists of three layers (Figure 6):

- GUI-layer: contains a process for each user or each session, which is linked to the core of the prototype via CORBA,

- Application-layer contains server-processes which offer services to each other and to the GUI-layer and

- Database-layer: manages persistent storage of all data.

At the time being, two production enterprises are testing the prototype.

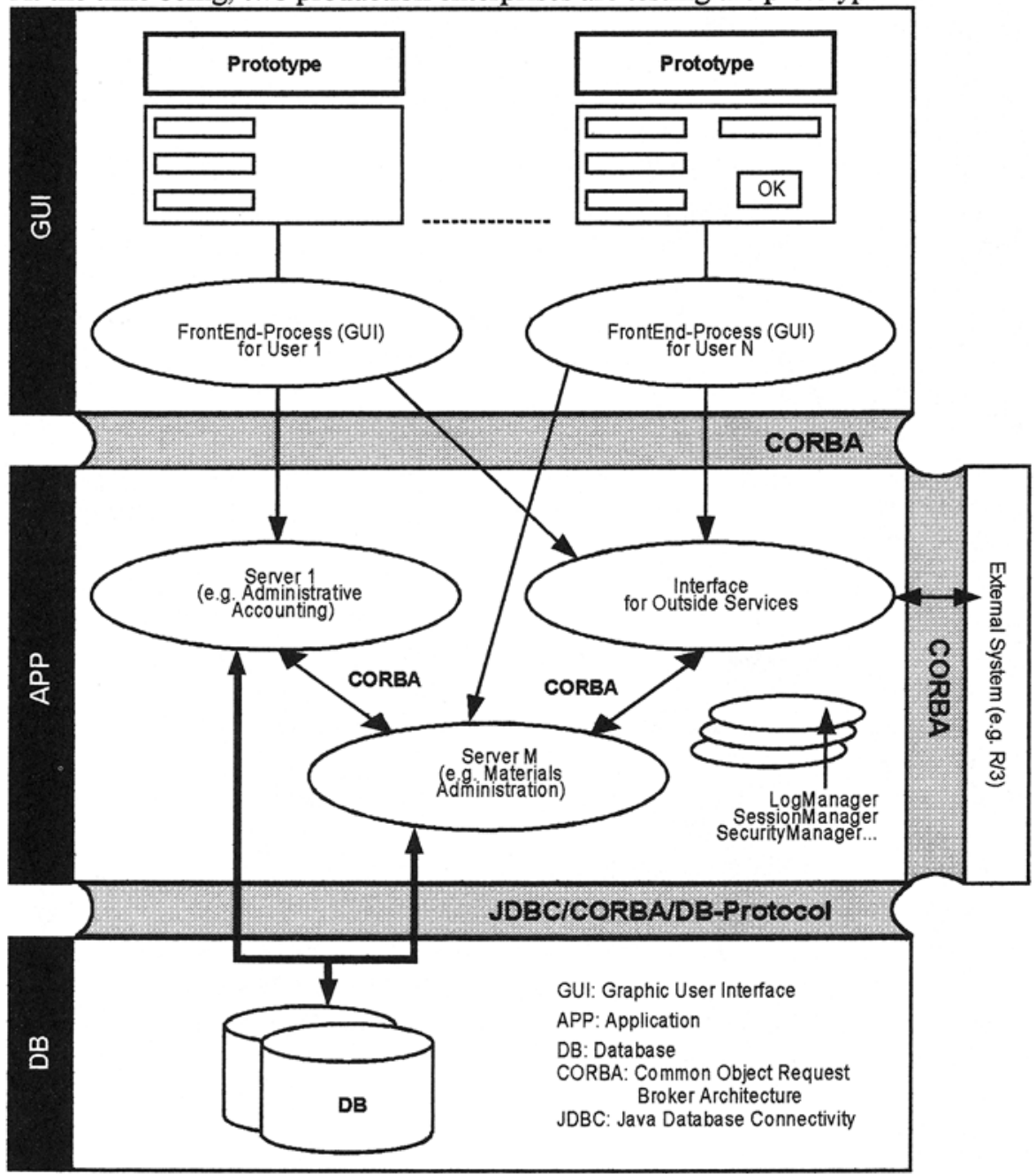

Figure 6 Software architecture. 


\section{References}

Aonix (1997) Software Through Pictures / Unified Modeling Language. Creating UML Models. Release 3.4. Aonix, San Francisco.

Booch, G. (1994) Objektorientierte Analyse und Design. Addison-Wesley Publishing Company, Bonn et al.

Borland (1997) Borland JBuilder für Windows 95 und Windows NT. Benutzerhandbuch. Borland International, Scotts Valley.

Ipro (1997) AENEIS 3.1. Benutzerhandbuch. IPRO Tool GmbH, Stuttgart.

Jacobson, I., Christerson, M., Jonsson, P., Övergaard, G. (1994) Object-Oriented Software Engineering. A Use Case Driven Approach. Addison-Wesley Publishing Company, Wokingham et al.

Jardin, C. A., Dixon, P. (1997) Symantec Visual Cafe Sourcebook. John Wiley \& Sons, New York et al.

Kees, A. (1996) METHPRO - Methodische Gestaltung der Prozesse zur integrierten Planung und Steuerung von PPS, IPS und QM, in Statusseminar des $B M B F$ - Softwaretechnologie (ed. U. Grote, G. Wolf), Projektträger Informationstechnik des BMBF bei der DLR, Berlin.

Kees, A. (1998a) Integrierte Planung und Steuerung: En Referenzmodell zur effizienten Auftragsabwicklung. $Z w F$ Zeitschrift für wirtschaftlichen Fabrikbetrieb, 3, 84-6.

Kees, A. (1998b) Entwicklung eines Verfahrens zur objektorientierten Modellierung der Produktionsplanung und -steuerung. Schriftenreihe Rationalisierung und Humanisierung (ed. W. Eversheim, H. Luczak), Shaker, Aachen.

Kees, A., Glaser, A. (1997) Oo und Java: Vom Modell zum System. Java Spektrum, 9, 16-21.

Luczak, H., Eversheim, W. (1998) Produktionsplanung und -steuerung. Grundlagen, Gestaltung und Konzepte. Springer, Berlin et al.

MKS (1997) MKS Source Integrity User Guide. Mortice Kern Systems Inc., Waterloo.

Poet (1997) Poet Java SDK. Programmer's Guide. Version 1.0. Poet Software, San Mateo.

Redlich, J.-P. (1996) CORBA 2.0. Praktische Einführung für $\mathrm{C}++$ und Java. Addison-Wesley Publishing Company, Bonn et al. 1996.

Rumbaugh, J., Blaha, M., Premerlani, W., Eddy, F., Lorensen, W. (1991) ObjectOriented Modeling and Design. Prentice Hall, Engelwood Cliffs.

Wirfs-Brock, R., Wilkerson, B., Wiener, L. (1993) Objektorientiertes SoftwareDesign. Hanser, München. 


\section{BIOGRAPHIES}

Dr.-Ing. Volker Stich studied mechanical engineering at Aachen. University of Technology (RWTH Aachen). He was working with the Research Institute for Rationalization and Operations Management (Forschungsinstitut für Rationalisierung, FIR) in Aachen from 1982 to 1986 as a scientific assistant. During this time. Dr. Stich was in charge of several research and industrial projects dealing with logistics, IT, information systems and personnel economics. From 1987 to 1996 he worked at the St. Gobain company where he later became the Logistic Manager for the German plants of Sekurit, and in 1994 he was appointed „Directeur d'études" for new international car projects in Germany, U.S.A., Mexico and Thailand. Since 1997, he has been the Managing Director of the FIR at Aachen, University of Technology.

Dipl-Ing, Alexandra Kees studied electrical engineering at Aachen, University of Technology (RWTH Aachen). She has been working with the Research Institute for Rationalization and Operations Management (Forschungsinstitut für Rationalisierung, FIR) in Aachen since 1993 as a scientific assistant in the department 'Production Management'. Mrs. Kees has been charged with the introduction of PPC-systems in numerous enterprises, with the development of reference processes for an integrated order processing for production, maintenance and quality management, and with the design of an object-oriented model for the production planning and control. 